Research Article

\title{
Experimental and Numerical Research on Defective Shield Segment under Cyclic Loading
}

\author{
Long-gang Tian $\mathbb{D}^{1},{ }^{1}$ Zhi-qiang $\mathrm{Hu} \mathbb{D}^{\mathbb{D}},{ }^{1}$ and Jie Chen $\mathbb{D}^{2}$ \\ ${ }^{1}$ School of Civil Engineering, Southeast University, Nanjing 211189, China \\ ${ }^{2}$ Key Laboratory of Earthquake Engineering and Engineering Vibration, Institute of Engineering Mechanics, CEA, \\ Harbin 150080, China \\ Correspondence should be addressed to Long-gang Tian; lgtian@seu.edu.cn
}

Received 8 June 2021; Accepted 24 June 2021; Published 5 July 2021

Academic Editor: Xuepeng Zhang

Copyright (c) 2021 Long-gang Tian et al. This is an open access article distributed under the Creative Commons Attribution License, which permits unrestricted use, distribution, and reproduction in any medium, provided the original work is properly cited.

\begin{abstract}
The retaining structure of a shield tunnel is usually subjected to static loading; however, cyclic loading such as the vibration loading of the train will act on the lining structure year after year that cannot be neglected. Due to the complex manufacturing and assembling process of the lining segment, initial defects in the segment are inevitable. Such defects will propagate under the cyclic loading such as the train vibration, which may cause a large threat to the shield tunnel system. In this paper, a defective shield tunnel lining segment under cyclic loading is studied by both a full-scale experiment and three-dimensional numerical simulations to investigate its fracture properties and failure mechanism and make a rational estimate of its fatigue life. Results show that crack propagation of the defective shield tunnel segment can be identified as several different stages based on its deformation characteristics, and the failure pattern of the segment is determined by its initial defects. The results by the experiment and numerical investigation are in good agreement for each other.
\end{abstract}

\section{Introduction}

Shield tunnel has been extensively adopted as the main form of the urban subway system during the past several decades. Usually, a shield tunnel is supported by the precast reinforced concrete lining segment to resist the substantial soil and water pressures surrounding the tunnel. These concrete segments are precast in factory and assembled in situ, which inevitably bring about initial defects such as small cracks in the lining segment. What is more, the surrounding pressures of shield tunnel lining such as the hydraulic pressure and temperature pressure change seasonally, and the vibration loading of the train acts on the lining structure day after day. These initial defects propagate stealthily under such cyclic loadings, which will weaken the safety level of the tunnel lining, and can even lead to total collapse for the tunnel in the worst situation.

With the increasing demand for shield tunnels in recent years, lots of experimental and numerical studies have been conducted to investigate the mechanical behaviour and failure mechanism of shield tunnel segments. Chen and Mo [1] adopted the 3D finite element method to analyse crack problems of shield tunnel at both the construction stage and service stage and testified that crack and breakage can be effectively reduced by improving the anticrack performance of the segment. Cividini et al. [2] studied on the reasons of a deep tunnel by both the in situ investigation and nonlinear finite element calculation, showing that the damages of the tunnel are related to incomplete filling of the gap. Some fullscale tests have been conducted by Ding et al. [3] to study the mechanical behaviours of the shield tunnel segment joints and proposed a mechanical model of the segment joints. Yang et al. [4] used the dynamic finite element method to analyse the segment opening distribution subjected to seismic loading. A new longitudinal model for shield tunnel was proposed in [5], which could consider the shearing dislocation between the lining rings of the tunnel structure. Li et al. [6] employed both analytical and experimental 
methods to study joint opening of a shield tunnel under different bending moments and under the ultimate limit state. Several model tests were conducted to study the failure mechanism of shield segments in sandy ground in [7], showing that removal of the segment may result in a sudden bending moment growth of the adjacent segments. Kavvadas et al. [8] investigated and compared three shield lining models consisting of continuous shell model, shell model with aligned joints, and shell model with staggered joints. Yang et al. [9] investigated the fracture of shield segments through a case study of the shield tunnel in Shanghai. A cyclic four-point bending test was conducted on a reinforced concrete beam and a smart shield tunnel lining segment using the optical fibre sensor to investigate the bending behaviour of reinforced concrete structures [10]. Based on an unloading situation, the bearing capacity of the shield tunnel structure was studied by performing some full-scale experiments [11]. Tian et al. [12, 13] conducted a series of prototype load tests and three-dimensional numerical experiments to investigate the failure mechanisms of cracked shield segments. Yan et al. [14] used the extended finite element method (XFEM) to explore the fracture properties of an underwater shield segment, and the impacting load of high-speed train was considered in this study. Through data analyses of acoustic emission, Wang et al. $[15,16]$ conducted some experimental studies on the damage evolution characteristics of shield tunnel segment with cracks. A novel multiscale modelling method was proposed by Wang et al. [17] to analyse the random propagation of multiple cracks and its mechanical behaviours of shield segments.

Performing fracture and fatigue analyses efficiently and precisely for three-dimensional structures with cracks is always a challenging subject in engineering. Plenty of effort has been made to obtain the advanced method for analysing three-dimensional crack problems, such as the embeddedsingularity elements $[18,19]$, the singular quarter-point elements [20, 21], the XFEM [22-27], and the symmetric Galerkin boundary element method-finite element method (SGBEM-FEM) alternating method [28-31]. Recently, Tian et al. [32-35] have made a series of two-dimensional and three-dimensional fatigue analyses on several kinds of typical structures in mechanical and civil engineering and obtained some useful results for the practical engineering.

In this paper, the defective shield segments under cyclic loading are studied by both a full-scale experiment and the three-dimensional numerical investigations. Three-dimensional numerical models of the defective lining segments are built using the SGBEM-FEM alternating method, and the stress intensity factors of the crack-front are captured by this method. The fatigue-crack propagation subjected to cyclic loading is depicted by the Paris exponential law. The results by the experiment and numerical simulation are compared and analysed, showing quite good agreement with each other.

\section{The Full-Scale Experiment}

2.1. Specimen Design and Equipment. The full-scale experiment of the defective shield tunnel segment is conducted with the real shield segment of Nanjing Metro Line 5. The outer diameter of the concrete lining ring is $6.2 \mathrm{~m}$, and the thickness of the segment is $0.35 \mathrm{~m}$. The length of each lining ring is $1.2 \mathrm{~m}$. The grade of the concrete strength is C55, with an elastic modulus of $3.55 \times 10^{4} \mathrm{MPa}$, and Poisson's ratio of 0.2 . The initial defects are two cut-through cracks along the length of the lining segment on its inner surface, with the depth of about $0.05 \mathrm{~m}$, which is shown in Figure 1 .

The loading device shown in Figure 2 is used to carry out the experiment. This specimen is subjected to the four-point bending, as illustrated in Figure 3, in which $P$ represents the vertical load and $N$ represents the axial load. The amplitude of the cyclic loading is set to $70 \%$ of the bearing capacity for the shield segment, and the stress ratio is set to 0.1 .

Only half of the shield segment is analysed due to the symmetrical property of the specimen. The moment in the middle of the specimen is illustrated in Figure 4 and expressed as follows:

$$
M=(P+W) L_{1}-P L_{2}-W L_{3}-N h_{1},
$$

where $N$ denotes the axial force and $M$ denotes the bending moment; $W$ represents the self-weight of the specimen and $P$ represents the prescribed vertical load.

According to (1), the vertical load can be expressed as follows:

$$
P=\frac{N\left(e+h_{1}\right)-W\left(L_{1}-L_{3}\right)}{\left(L_{1}-L_{2}\right)},
$$

where $e=M / N$, which is defined as the loading eccentricity. For this full-scale experiment, $e$ is set to $0.24 \mathrm{~m}$.

In this experiment, the parameters to be measured include the load, displacement, surface strain of the concrete, and crack mouth opening displacement (CMOD). The load is directly captured with the controlling computer and the concrete strain is measured with resistance strain gauge. CMOD and displacement of the segment are captured by the displacement meter. Figures 5-7 show the related devices used in this experiment.

2.2. Observed Phenomena of the Experiment. For this initially defective shield segment, the initial cracks start to grow as their stress intensity factors reach the concrete's fracture toughness and show very typical I-type fracture characteristics. The cracking stages of the specimen during the entire loading process can be identified as several different phases based on its deformation characteristics, which include (a) the initial crack stage; (b) the crack developing stage; (c) the stable crack growth; (d) the unstable crack growth; and (e) the final collapse. Figure 8 shows the captured pictures of the crack propagation and final failure mode for the specimen. The defective shield segment demonstrates some I-type fracture properties, and the collapse pattern of the segment is determined by its initial defects.

Both the specimen (including the defects) and the load are symmetrical, so the deformation and crack propagation will show some symmetrical properties, theoretically. However, it is very hard, sometimes even impossible, to make the material homogeneous of the specimen in practical 


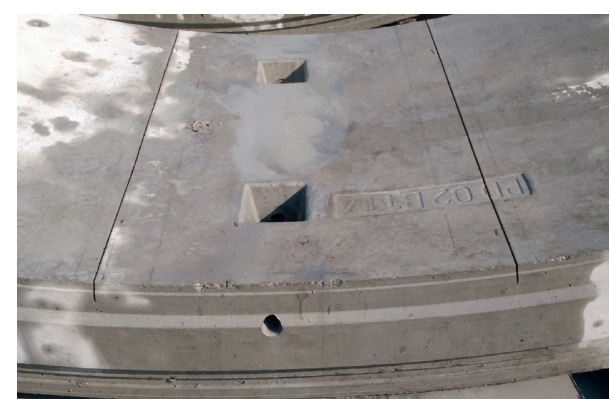

Figure 1: The defective shield tunnel segment.

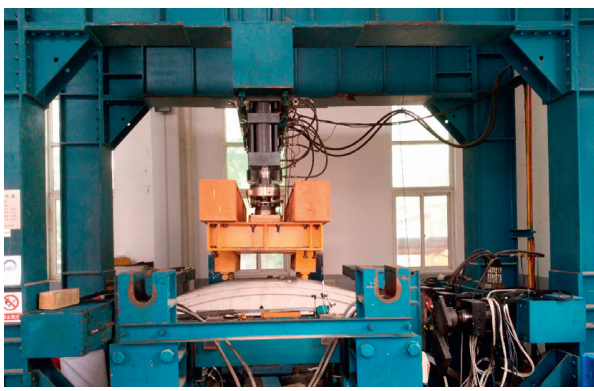

Figure 2: Loading system of the full-scale experiment.

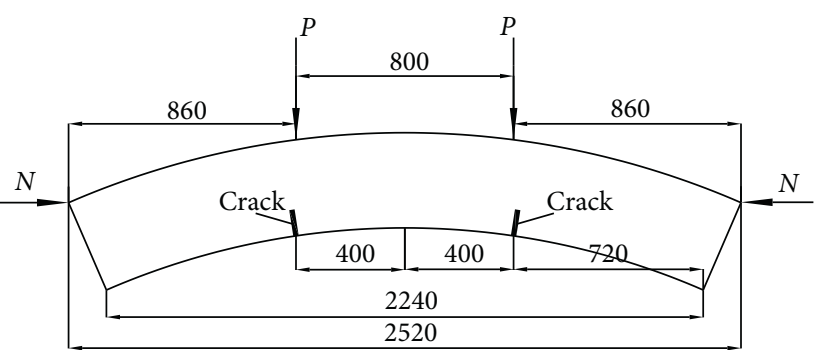

FIGURE 3: Sketch of the defective shield segment (unit: $\mathrm{mm}$ ).

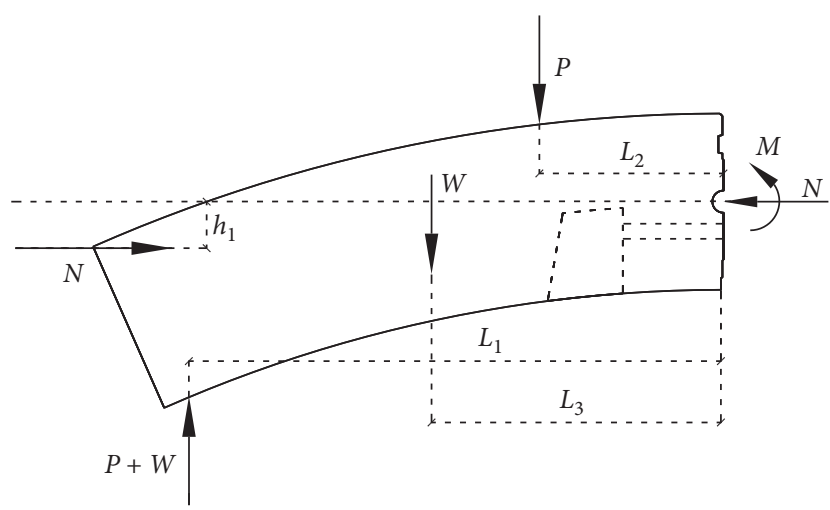

FIGURE 4: Half of the specimen is used for the force analysis.

engineering. It is also difficulty to set the loads absolutely symmetrical for the specimen. Hence, the actual deformation characteristic and collapse pattern of the specimen demonstrate some unsymmetrical and unbalanced properties to a certain extent.

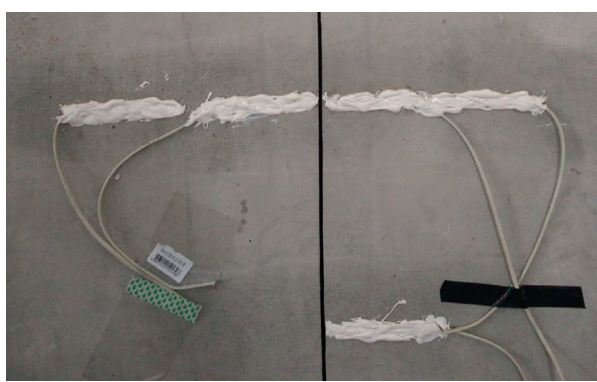

FiguRE 5: Measuring concrete strain using strain gauge.

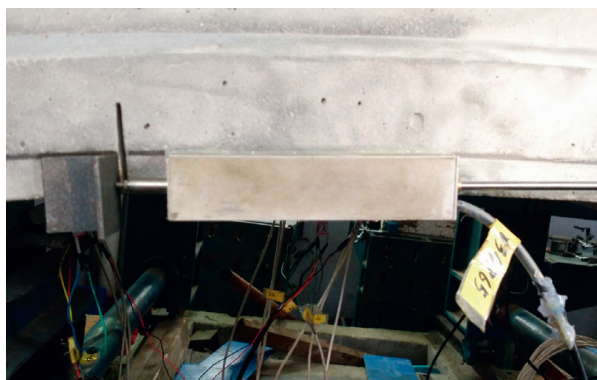

Figure 6: Measuring CMOD of the segment with displacement meter.

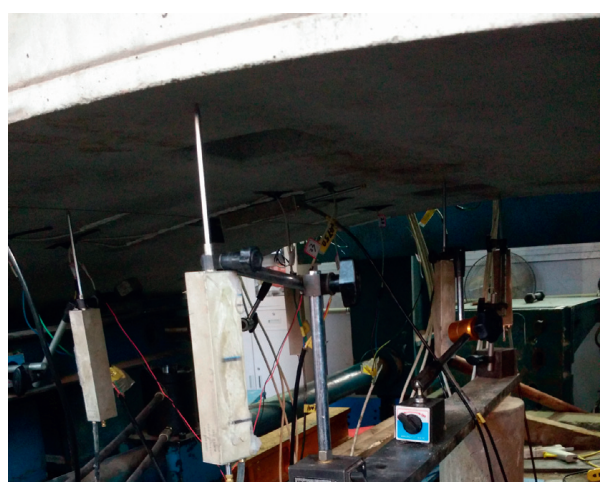

FIGURE 7: Measuring vertical displacement of the segment with displacement meter.

2.3. Experiment Results and Analysis. The double-K fracture criterion [36] is used to analyse fatigue and fracture characteristics of the specimen. As with the propagating process of the crack, the load which impels the initial crack to begin growing is defined as cracking load, and the load which the specimen can finally endure is defined as ultimate load. The variation of $C M O D$ and the vertical displacement of the specimen is illustrated in Figure 9, and the load versus stain near the crack-front is demonstrated in Figure 10. In Figure 9, we can obtain the cracking load by searching for the first turning point on CMOD curve. For the curves in Figure 10, the cracking load can also be acquired by searching for these turning points. The results of cracking load for the specimen are listed in Table 1 and good agreement can be reached. 


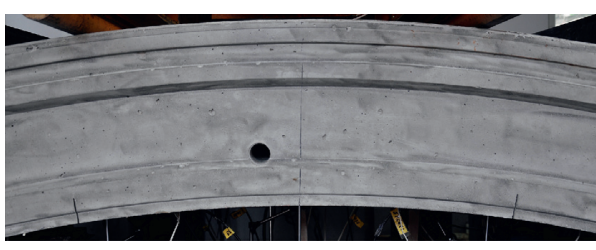

(a)

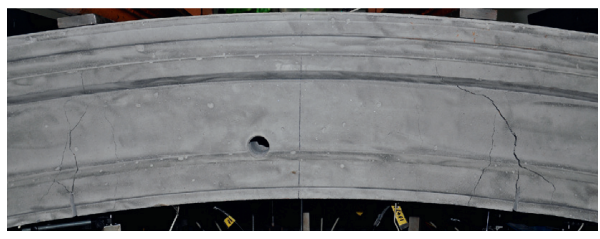

(c)

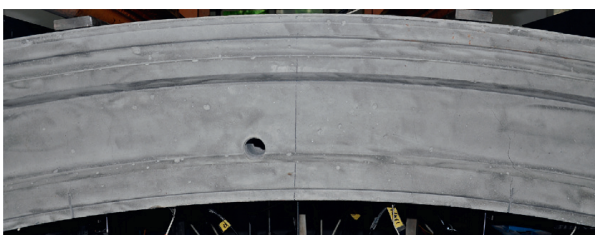

(b)

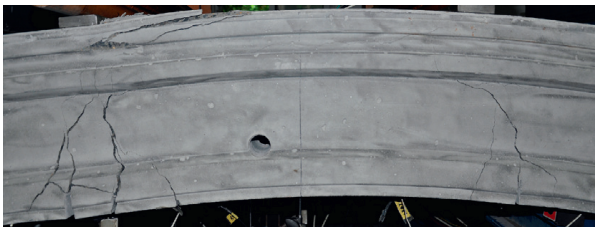

(d)

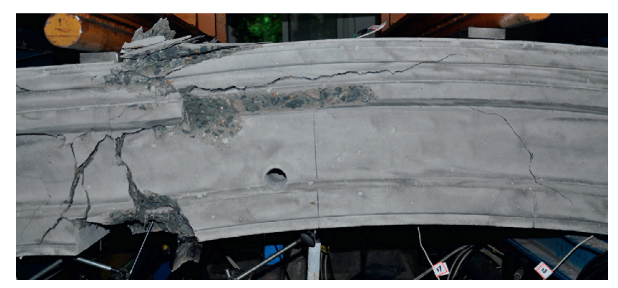

(e)

Figure 8: The deformation and failure process of the defective specimen.

\section{The Numerical Investigation}

3.1. Numerical Model. The numerical model for the defective shield segment is built according to the full-scale experiment as described in Section 2. The global structure with no crack is modelled with the 10-noded tetrahedron element, and the initial crack surface is modelled with the 8-noded quadrilateral elements, independently. The numerical model is shown in Figure 11 and quite coarse meshes are used for the simulation.

3.2. Segment Bearing Capacity. The fracture toughness for concrete C55 is $K_{\mathrm{Ic}}^{\mathrm{ini}}=0.53 \times 10^{6} \mathrm{~Pa} \sqrt{\mathrm{m}}$ and $K_{\mathrm{Ic}}^{\mathrm{un}}=1.42 \times$ $10^{6} \mathrm{~Pa} \sqrt{\mathrm{m}}$ based on the double-K fracture criterion of concrete. Three-dimensional SGBEM-FEM alternating method is employed to capture the stress intensity factors at the crack-front.

The efficient stress intensity factor for this problem is defined as follows:

$$
K_{\text {eff }}=\sqrt{K_{\mathrm{I}}^{2}+K_{\mathrm{II}}^{2}+\frac{K_{\mathrm{III}}^{2}}{1-v}}
$$

where $K_{\mathrm{I}}, K_{\mathrm{II}}$, and $K_{\mathrm{III}}$ are the stress intensity factors for fracture mode I, II, and III, respectively.

The initial cracking load $N_{\text {ini }}$ and $P_{\text {ini }}$, and the ultimate load $N_{\text {un }}$ and $P_{\text {un }}$ can be obtained by constantly changing their values, until the computed stress intensity factors approach the fracture toughness of concrete C55. Computed cracking loads for this numerical model are

$$
\frac{N_{\text {ini }}=290 \mathrm{kN}, P_{\text {ini }}=147.725 \mathrm{kN}, K_{\text {eff }}=0.5304 \times 10^{6} \mathrm{~Pa} \sqrt{\mathrm{m}}}{N_{\max }=700 \mathrm{kN}, P_{\max }=370.296 \mathrm{kN}, K_{\text {eff }}=1.436 \times 10^{6} \mathrm{~Pa} \sqrt{\mathrm{m}}} .
$$

3.3. Structure Reaction under Cyclic Load. The surrounding pressures of shield tunnel lining segment, such as the water pressure and temperature pressure, usually change seasonally. Moreover, the vibration loading of the train will act on the lining structure in the long term that cannot be neglected. These various kinds of load will cause the fatiguerelated problems, which, on one hand, may initiate microcrack inside the concrete segment of the shield tunnel and propagate the existing cracks on the other hand. Therefore, it has significant meaning to investigate the fracture and fatigue mechanism of defective shield tunnel segment under cyclic loading.

For the concrete shield tunnel segment with initial defects, its Paris fatigue law is expressed as follows [37]:

$$
\frac{\mathrm{d} a}{\mathrm{~d} N}=3.43 \times 10^{-3}(\Delta K)^{-17.393\left(a_{0} / D\right)+12.844},
$$

where $\mathrm{d} a / \mathrm{d} N$ denotes the crack growth rate, $\Delta K$ is the range of stress intensity factors, $a_{0}$ denotes the initial crack depth, and $D$ denotes the thickness of the specimen.

The amplitude of the cyclic loading is $70 \%$ of the bearing capacity for the shield segment, and the stress ratio is 0.1 . Numerical model mentioned above is studied under such cyclic loading. The crack growth versus load cycles is 


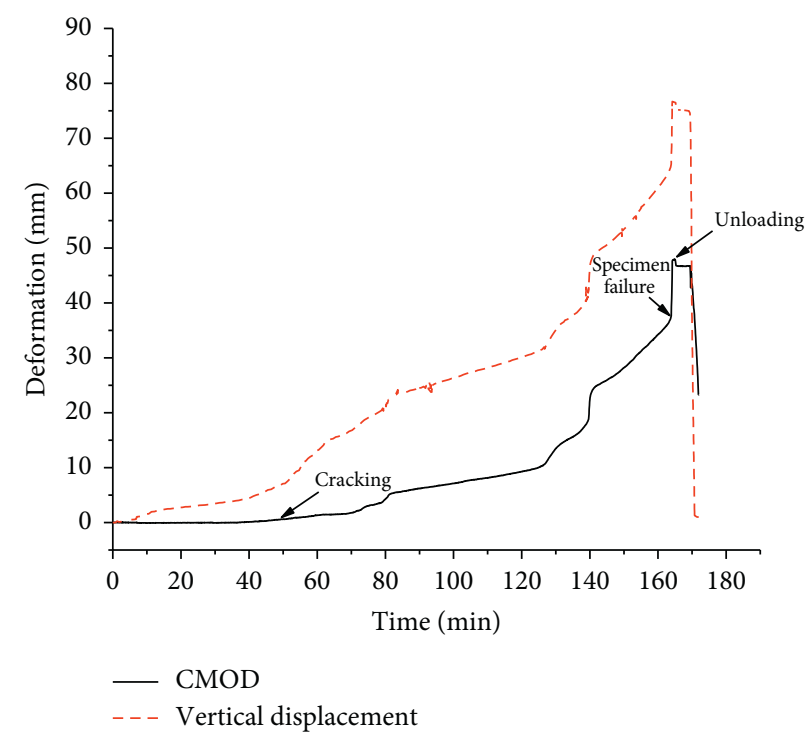

Figure 9: CMOD and vertical displacement of the specimen.

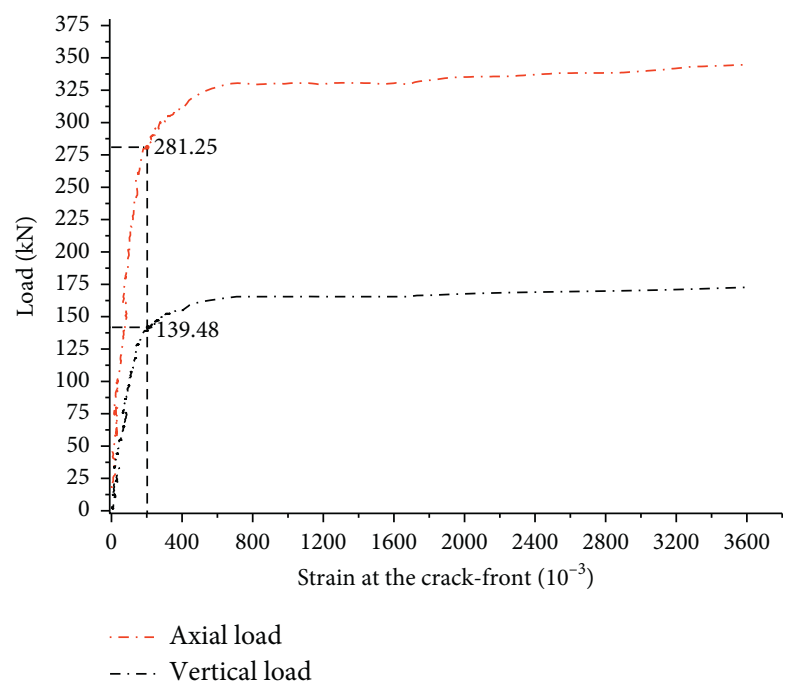

FIGURE 10: Load versus strain at the crack-front of the specimen.

TABLE 1: The cracking loads of the shield segment by the experiment.

\begin{tabular}{lcc}
\hline Method & & The cracking loads \\
& Axial load $(\mathrm{kN})$ & Vertical load $(\mathrm{kN})$ \\
\hline CMOD-time curve & 269.22 & 143.60 \\
Load-strain curve & 281.25 & 139.48 \\
Error (\%) & 4.28 & 2.87 \\
\hline
\end{tabular}

illustrated in Figure 12. The stress intensity factor at the crack-front approaches the fracture toughness of concrete C55 after about $1.51 \times 10^{7}$ load cycles, thus the segment is broken. The total fatigue-crack increment is $0.067 \mathrm{~m}$.

The final form of the crack in shield segment in a twodimensional view is illustrated in Figure 13, and the threedimensional fatigue-crack propagation is demonstrated in Figure 14, which approximatively demonstrates the I-type fracture of the defective shield tunnel segment. The initial defect does not strictly extend along its initial path; in fact, it slightly propagates to the middle of the segment.

3.4. Results and Discussion. The cracking loads for the defective tunnel segment by numerical simulation in Section 3.2 are compared with those by the experiment in Section 2.3, which are listed in Table 2; also, good agreement can be reached for each other. 


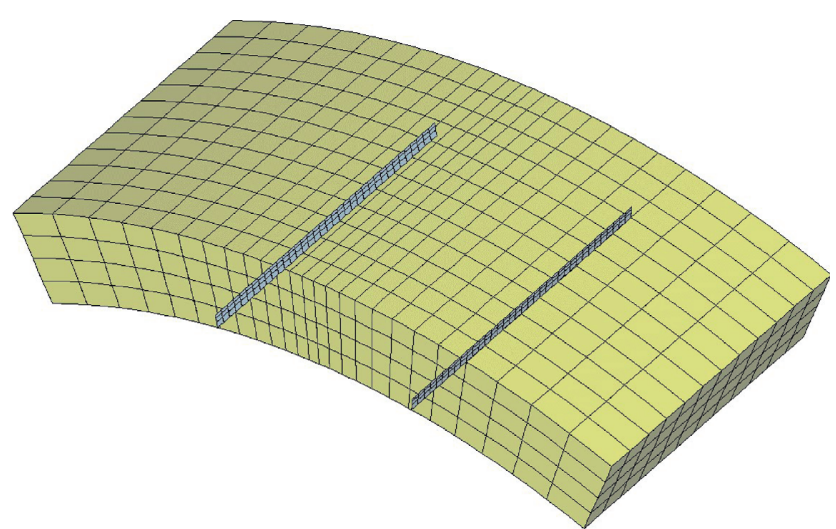

FIgURE 11: Numerical model for the defective shield segment.

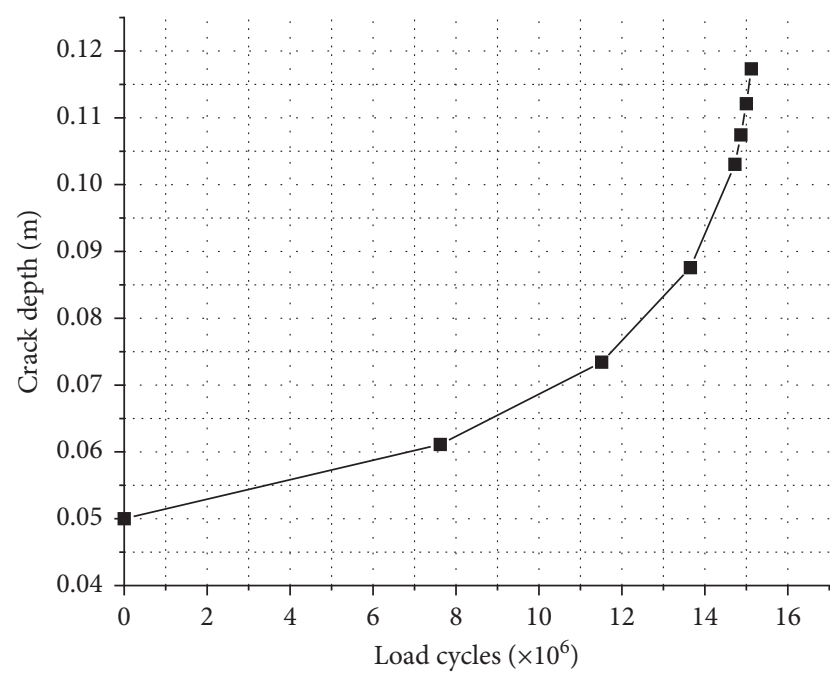

FIGURE 12: The crack growth versus number of load cycles.

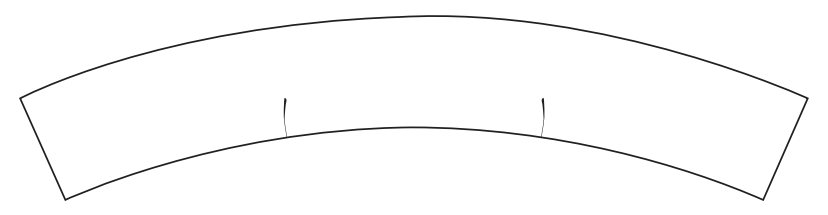

Figure 13: The final crack in the segment, a $2 \mathrm{D}$ view.

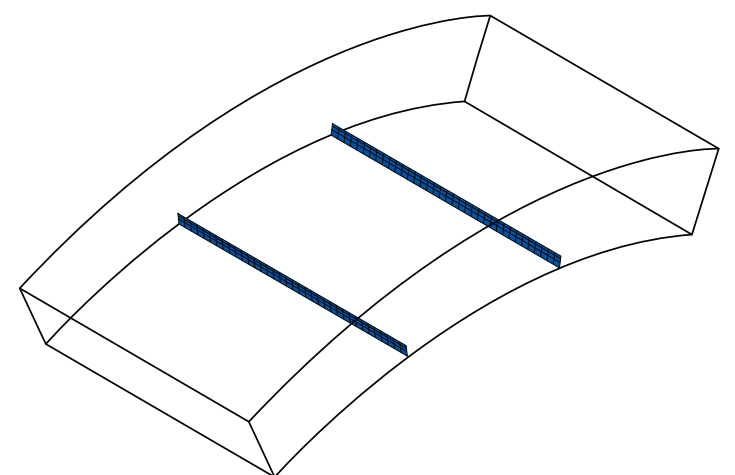

(a)

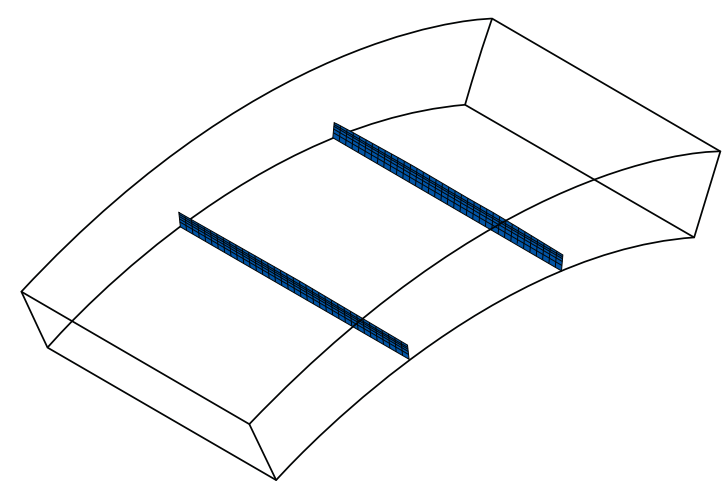

(b)

FIgURE 14: Continued. 


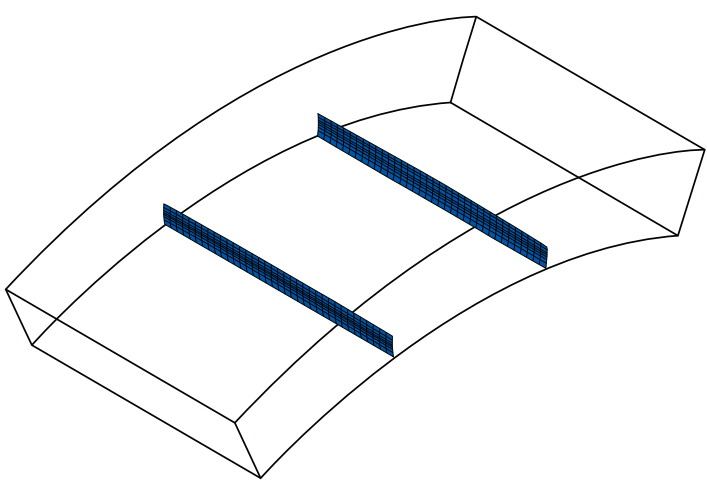

(c)

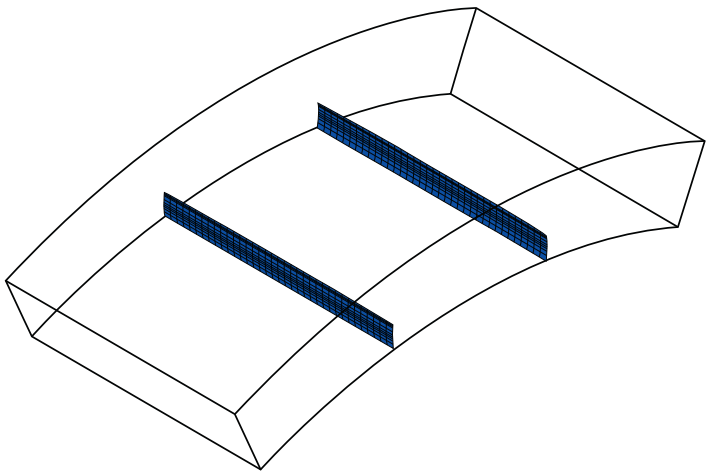

(e)

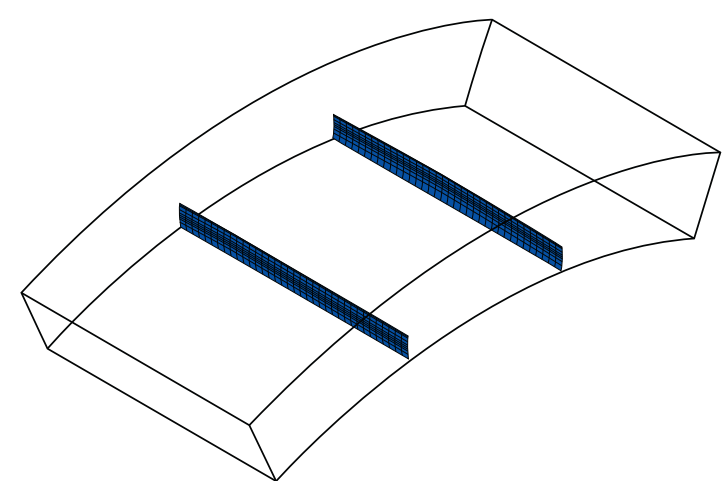

(d)

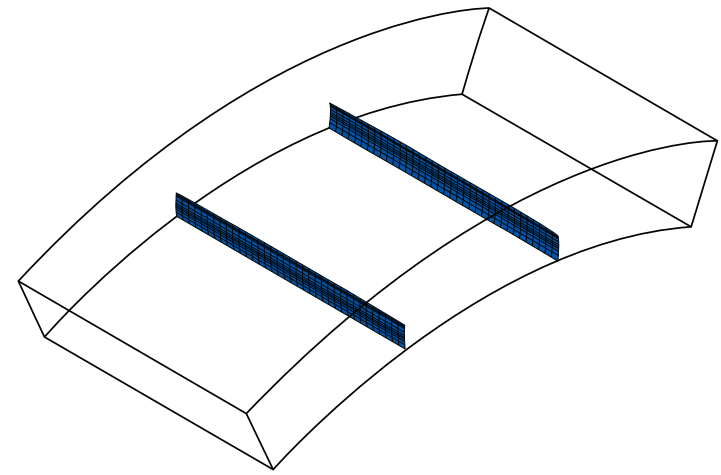

(f)

FIgURE 14: Fatigue-crack propagation of the segment under cyclic loading, a 3D view.

TABle 2: Comparison of the cracking loads between numerical and experimental results.

\begin{tabular}{lcc}
\hline Method & & Cracking loads \\
& Axial load $N_{\text {ini }}(\mathrm{kN})$ & Vertical load $P_{\text {ini }}(\mathrm{kN})$ \\
\hline By the load-strain curve & 281.25 & 139.48 \\
By numerical simulation & 290.00 & 147.73 \\
Error (\%) & 3.11 & 5.91 \\
By the CMOD-time curve & 269.22 & 143.60 \\
By numerical simulation & 290.00 & 147.73 \\
Error (\%) & 7.16 & 2.80 \\
\hline
\end{tabular}

\section{Conclusions}

In this paper, a full-scale experiment of the defective shield tunnel segment is conducted, and its corresponding threedimensional numerical model is built by using the threedimensional SGBEM-FEM alternating method. The fracture properties and bearing capacity of the initially defective shield segment under cyclic loading are studied by both the experiment and the numerical simulation. The following conclusions can be drawn:

(1) Crack propagation of the defective shield segment can be identified as several different stages based on its deformation characteristics, which include the initial crack stage, the crack developing stage, the stable crack growth, the unstable crack growth, and the final collapse.
(2) The complete crack propagation up to collapse of the shield segment can be conveniently and efficiently simulated by the SGBEM-FEM alternating method, which is similar with that by the experiment.

(3) The shield segment with initial defects approximatively demonstrates the I-type fracture properties under the cyclic loading, and the final failure mode of the segment is mainly determined by its initial defects.

(4) The cracking loads for the defective shield segment are acquired by both the experiment and numerical investigation, and good agreement can be reached for each other.

Some three-dimensional effects are neglected in this study, such as the three-dimensional corner singularity, 
existence of a critical angle at which crack-front intersects the free surface, and coupling of mode I, II, and III, since they have insignificant effects for fracture and fatigue analysis of the cracked structures. Also, crack closure induced by plasticity can be helpful to consider the influence of thickness of the structure on the crack propagation rates. Very simple Paris fatigue law is employed to predict the fatigue propagation rate in this study; however, other complex models which consider the effect of structure thickness can also be incorporated in the current framework of SGBEM-FEM alternating method, which will be our study in the future.

\section{Data Availability}

The data used to support the findings of this study are included within the article.

\section{Conflicts of Interest}

The authors declare no conflicts of interest.

\section{Acknowledgments}

The research described in this paper was financially supported by the National Natural Science Foundation of China (grant no. 51808114) and Natural Science Foundation of Jiangsu Province (grant no. BK20170670).

\section{References}

[1] J. S. Chen and H. H. Mo, "Numerical study on crack problems in segments of shield tunnel using finite element method," Tunnelling and Underground Space Technology, vol. 24, no. 1, pp. 91-102, 2009.

[2] A. Cividini, A. Contini, L. Locatelli, and G. Gioda, "Investigation on the cause of damages of a deep tunnel," International Journal of Geomechanics, vol. 12, no. 6, pp. 722-731, 2012.

[3] W.-Q. Ding, Y.-C. Peng, Z.-G. Yan, B.-W. Shen, H.-H. Zhu, and X.-X. Wei, "Full-scale testing and modeling of the mechanical behavior of shield TBM tunnel joints," Structural Engineering \& Mechanics, vol. 45, no. 3, pp. 337-354, 2013.

[4] C. S. Yang, H. H. Mo, J. S. Chen, and Y. Z. Wang, "Influence of seismic loading on segment opening of a shield tunnel," Science World Journal, vol. 2014, Article ID 387210, 9 pages, 2014.

[5] H.-N. Wu, S.-L. Shen, S.-M. Liao, and Z.-Y. Yin, "Longitudinal structural modelling of shield tunnels considering shearing dislocation between segmental rings," Tunnelling and Underground Space Technology, vol. 50, pp. 317-323, 2015.

[6] X. Li, Z. Yan, Z. Wang, and H. Zhu, "Experimental and analytical study on longitudinal joint opening of concrete segmental lining," Tunnelling and Underground Space Technology, vol. 46, pp. 52-63, 2015.

[7] G. Zheng, T. Cui, X. Cheng et al., "Study of the collapse mechanism of shield tunnels due to the failure of segments in sandy ground," Engineering Failure Analysis, vol. 79, pp. 464-490, 2017.

[8] M. Kavvadas, D. Litsas, I. Vazaios, and P. Fortsakis, "Development of a $3 \mathrm{D}$ finite element model for shield $\mathrm{EPB}$ tunnelling," Tunnelling and Underground Space Technology, vol. 65, pp. 22-34, 2017.

[9] Y. Yang, B. Zhou, X. Xie, and C. Liu, "Characteristics and causes of cracking and damage of shield tunnel segmented lining in construction stage-a case study in Shanghai soft soil," European Journal of Environmental and Civil Engineering, vol. 22, no. 1, pp. s213-s227, 2018.

[10] W.-C. Cheng, J. C. Ni, and S.-L. Shen, "Experimental and analytical modeling of shield segment under cyclic loading," International Journal of Geomechanics, vol. 17, no. 6, Article ID 04016146, 2017.

[11] X. Liu, Z. Dong, Y. Bai, and Y. Zhu, "Investigation of the structural effect induced by stagger joints in segmental tunnel linings: first results from full-scale ring tests," Tunnelling and Underground Space Technology, vol. 66, pp. 1-18, 2017.

[12] L. G. Tian, Q. Zhang, X. Wang, and G. Zhang, "A prototype load test on fracture and damage properties of cracked shield tunnel lining segments," in Proceedings of the Geoshanghai International Conference, Springer, Shanghai, China, May 2018.

[13] L. G. Tian, X. Wang, and Z. L. Cheng, "Numerical study on the fracture properties of concrete shield tunnel lining segments," Geofluids, vol. 2021, Article ID 9975235, 11 pages, 2021.

[14] Q. Yan, Y. Xu, W. Zhang, P. Geng, and W. Yang, "Numerical analysis of the cracking and failure behaviors of segmental lining structure of an underwater shield tunnel subjected to a derailed high-speed train impact," Tunnelling and Underground Space Technology, vol. 72, pp. 41-54, 2018.

[15] S. Wang, C. Liu, G. Ma et al., "Experimental investigation on the influence of regional concrete spalling on shield tunnel segments," Advances in Civil Engineering, vol. 2019, Article ID 1829124, 15 pages, 2019.

[16] S. Wang, C. Liu, Z. Shao, G. Ma, and C. He, "Experimental study on damage evolution characteristics of segment structure of shield tunnel with cracks based on acoustic emission information," Engineering Failure Analysis, vol. 118, Article ID 104899, 2020.

[17] F.-Y. Wang, M.-L. Zhou, D.-M. Zhang, H.-W. Huang, and D. Chapman, "Random evolution of multiple cracks and associated mechanical behaviors of segmental tunnel linings using a multiscale modeling method," Tunnelling and Underground Space Technology, vol. 90, pp. 220-230, 2019.

[18] P. Tong, T. H. H. Pian, and S. J. Lasry, "A hybrid-element approach to crack problems in plane elasticity," International Journal for Numerical Methods in Engineering, vol. 7, no. 3, pp. 297-308, 1973.

[19] S. N. Atluri, A. S. Kobayashi, and M. Nakagaki, “An assumed displacement hybrid finite element model for linear fracture mechanics," International Journal of Fracture, vol. 11, no. 2, pp. 257-271, 1975.

[20] R. D. Henshell and K. G. Shaw, "Crack tip finite elements are unnecessary," International Journal for Numerical Methods in Engineering, vol. 9, no. 3, pp. 495-507, 1975.

[21] R. S. Barsoum, "Application of triangular quarter-point elements as crack tip elements of power law hardening material," International Journal of Fatigue, vol. 12, pp. 463-446, 1976.

[22] N. Sukumar, N. Moës, B. Moran, and T. Belytschko, "Extended finite element method for three-dimensional crack modelling," International Journal for Numerical Methods in Engineering, vol. 48, no. 11, pp. 1549-1570, 2000.

[23] N. Moës and T. Belytschko, "Extended finite element method for cohesive crack growth," Engineering Fracture Mechanics, vol. 69, no. 7, pp. 813-833, 2002. 
[24] I. V. Singh, B. K. Mishra, S. Bhattacharya, and R. U. Patil, "The numerical simulation of fatigue crack growth using extended finite element method," International Journal of Fatigue, vol. 36, no. 1, pp. 109-119, 2012.

[25] A. Jameel and G. A. Harmain, "Modeling and numerical simulation of fatigue crack growth in cracked specimens containing material discontinuities," Strength of Materials, vol. 48, no. 2, pp. 294-307, 2016.

[26] A. Bergara, J. I. Dorado, A. Martin-Meizoso, and J. M. Martínez-Esnaola, "Fatigue crack propagation in complex stress fields: experiments and numerical simulations using the extended finite element method (XFEM)," International Journal of Fatigue, vol. 103, pp. 112-121, 2017.

[27] G. Liu, D. Zhou, J. Guo, Y. Bao, Z. Han, and J. Lu, "Numerical simulation of fatigue crack propagation interacting with micro-defects using multiscale XFEM," International Journal of Fatigue, vol. 109, pp. 70-82, 2018.

[28] G. P. Nikishkov, J. H. Park, and S. N. Atluri, "SGBEM-FEM alternating method for analyzing 3D non-planar cracks and their growth in structural components," Computer Modeling in Engineering and Sciences, vol. 2, pp. 401-422, 2001.

[29] Z. D. Han and S. N. Atluri, "SGBEM (for cracked local subdomain)-FEM (for uncracked global structure) alternating method for analyzing $3 \mathrm{~d}$ surface cracks and their fatiguegrowth," Computer Modeling in Engineering and Sciences, vol. 3, pp. 699-716, 2002.

[30] Z. D. Han and S. N. Atluri, "On simple formulations of weakly-singular traction \& displacement bie, and their solutions through petrov-galerkin approaches," Computer Modeling in Engineering and Sciences, vol. 4, pp. 5-20, 2003.

[31] Z. D. Han and S. N. Atluri, "A systematic approach for the development of weakly-singular BIEs," Computer Modeling in Engineering and Sciences, vol. 21, pp. 41-52, 2007.

[32] L. Tian, L. Dong, S. Bhavanam, N. Phan, and S. N. Atluri, "Mixed-mode fracture \& non-planar fatigue analyses of cracked I-beams, using a 3D SGBEM-FEM Alternating Method," Theoretical and Applied Fracture Mechanics, vol. 74, pp. 188-199, 2014.

[33] L.-G. Tian, L.-T. Dong, N. Phan, and S. N. Atluri, "Non-planar mixed-mode growth of initially straight-fronted surface cracks, in cylindrical bars under tension, torsion and bending, using the symmetric Galerkin boundary element methodfinite element method alternating method," Fatigue and Fracture of Engineering Materials and Structures, vol. 38, no. 8, pp. 923-935, 2015.

[34] L. Tian, L. Dong, N. Phan, and S. N. Atluri, "Three-dimensional SGBEM-FEM alternating method for analyzing fatigue-crack growth in and the life of attachment lugs," Journal of Engineering Mechanics, vol. 141, no. 4, Article ID 04014142, 2015.

[35] L. G. Tian and Z. L. Cheng, "Fracture and fatigue analyses of cracked structures using the iterative method," Geofluids, vol. 2021, Article ID 4434598, 12 pages, 2021.

[36] S. L. Xu, "The calculation approaches of double-k fracture parameters of concrete and a possible coding standard test method for determining them," Journal of China Three Gorges University, vol. 1, pp. 1-8, 2002.

[37] X. J. Lu, "Study on the fatigue fracture of concrete and its size effect," MS thesis, Dalian University of Technology, Dalian, China, 2000. 